\title{
Gender-specific external barriers to seeking care for urinary incontinence
}

\author{
This article was published in the following Dove Press journal: \\ Patient Preference and Adherence \\ 31 October 2012 \\ Number of times this article has been viewed
}

\author{
Jan Svihra' \\ Jan Luptak' \\ Viera Svihrova ${ }^{2}$ \\ Dusan Mesko ${ }^{3}$ \\ 'Department of Urology, ${ }^{2}$ Department \\ of Public Health, ${ }^{3}$ Department of \\ Sports Medicine, Jessenius School of \\ Medicine, Martin, Slovak Republic
}

Correspondence: Jan Svihra

Department of Urology, Jessenius School of Medicine, Kollarova 2, 03659 Martin,

Slovak Republic

Tel +42I 905369 I55

$\mathrm{Fax}+42$ I 434133034

Emailsvihra@jfmed.uniba.sk
Background: Barriers to seeking care for urinary incontinence are specific, objective, external conditions that prevent incontinence sufferers from seeking treatment. The aim of this study was to compare barriers, gender, and health care disparities in incontinence sufferers.

Methods: Incontinent patients were recruited into a questionnaire-based cross-sectional study. The 14-item Barriers to Incontinence Care Seeking Questionnaire (BICS-Q) and the three-item International Consultation on Incontinence Questionnaire-Urinary Incontinence Short Form (ICIQ-UI SF) were used to evaluate barriers to seeking health care for urinary incontinence.

Results: The representative sample $(n=1014)$ finally included 567 adults eligible to participate in this study (response rate 55.9\%). Of the 147 incontinent males, 93 (63.3\%) did not seek care, and of the 420 incontinent females, 282 (67.1\%) did not seek care. Untreated males had significantly higher BICS-Q scores than other patients. Risk factors for barriers were obesity (odds ratio 2.13 for females versus 0.83 for males), stress urinary incontinence (1.57 versus 9.38 , respectively), and urgency urinary incontinence (2.40 versus 1.75 ).

Conclusion: The barriers to seeking care for urinary incontinence seem to be gender-specific. Obese females with urgency urinary incontinence and males with stress urinary incontinence were least likely to seek treatment.

Keywords: urinary incontinence, barriers, health behavior, seeking, care

\section{Introduction}

Urinary incontinence, defined as the involuntary leakage of urine, is a common health problem. ${ }^{1}$ Urinary incontinence can be described according to type, frequency, severity, precipitating factors, social impact, effect on hygiene and quality of life, measures used to contain leakage, and whether or not the individual seeks or desires help because of urinary incontinence. ${ }^{2,3}$

Stress urinary incontinence refers to involuntary leakage on effort or exertion, or on sneezing or coughing. Urgency urinary incontinence refers to involuntary leakage accompanied by or immediately preceded by urgency. Urgency urinary incontinence can present as frequent small losses between micturition or as a catastrophic leakage with complete bladder emptying. 1,3

Large, population-based epidemiological studies have shown a high prevalence and incidence of urinary incontinence in different age groups, genders, and races, and in individuals with certain diseases. ${ }^{2}$ Urinary incontinence has a significant impact on quality of life, as measured by specific questionnaires in many epidemiological studies. ${ }^{4}$ 
Barriers to seeking care for urinary incontinence are external conditions that prevent sufferers from seeking care, such as transportation or health insurance (external barriers). Such barriers differ from internal conditions, ie, attitudes that prevent incontinence sufferers from seeking care, such as embarrassment, fear, or anxiety (internal barriers). ${ }^{5}$ Quality of health care can be measured according to the barriers that prevent incontinent patients from seeking care. Different surveys have focused on seeking care, but none have operationalized barriers to care for sufferers. Barrier operationalization allows investigators to minimize confounding bias by adjusting for this independent variable in analyzing the relationship between ethnicity, incontinence type, continence surgery, and other factors. ${ }^{5}$

The Barriers to Incontinence Care Seeking Questionnaire (BICS-Q) was created by Heit et al as a valid tool for measurement of external barriers to seeking care. It was developed using the principle of Melnyk's Barriers Scale to operationalize the concept of barriers as perceptions of cost or obstacles to care by the consumer. ${ }^{5}$ The International Consultation on Incontinence Questionnaire-Urinary Incontinence Short Form (ICIQ-UI SF) was created for the basic evaluation of urinary incontinence, especially in primary care. ${ }^{6,7}$ Both questionnaires have been validated for studying the seeking of health care by incontinent patients. ${ }^{8,9}$ Questionnaires allow for the study of different aspects of urinary incontinence among participants in large epidemiological studies. ${ }^{5,6}$ The aim of this study was to compare barriers, gender, and health care disparities in an adult population with urinary incontinence.

\section{Materials and methods Population}

This cross-sectional study was conducted in randomly selected primary care clinics in a central European country from March to June 2009. Specific barriers to seeking care were analyzed in a group of patients with urinary incontinence. Adult men and women of all ages were included in this questionnaire-based study. Participants were randomly selected from the patient lists of county outpatient clinics. Every odd patient was included if they had experienced at least one episode of urinary incontinence in the previous month. Exclusion criteria were treatment for urinary incontinence at the time of consultation, refusal to participate in the study, absence of urinary incontinence, and deterioration of cognitive function. The study was approved by the local ethics committee. Informed consent, required by the institutional review board, was obtained for each study participant.
The estimated prevalence of urinary incontinence in middle-aged and older women ranges from $30 \%$ to $60 \%$, and the prevalence increases with age. The epidemiology of urinary incontinence in males has not been investigated to the same extent as in females, but the limited evidence suggests that urinary incontinence is at least twice as prevalent in women as in men. ${ }^{2}$ The sample size was established based on the estimated prevalence of urinary incontinence. A sample of 121 cases for each gender was necessary to achieve an $80 \%$ power to detect a difference by gender. Statistical significance was set at 0.05 (type I error rate).

\section{Procedure and measures}

Patients completed a paper-based questionnaire after consultation with their general practitioner. Sampling was completed during a one-week period with each physician. The period of sampling was March to June 2009. The questionnaires were collected by a researcher after each physician had evaluated his or her final patient, and included in the study database.

Two validated questionnaires were used to measure barriers to seeking care for urinary incontinence. The BICS-Q consists of a 14-item scale with items related to relationship, cost, health care site, fear, and convenience (see Table 1). An overall BICS-Q score is calculated as the summation of subscale scores. Higher barrier scores are associated with

Table I Barriers to Incontinence Care Seeking Questionnaire (patients with any positive answer)

\begin{tabular}{|c|c|}
\hline How much of a barrier to seeking care is: & n (\%) \\
\hline $\begin{array}{l}\text { I don't have a health care practitioner who will see me } \\
\text { for uncontrollable urine leakage }\end{array}$ & $150(26.5)$ \\
\hline $\begin{array}{l}\text { There are long delays before insurance repays } \\
\text { out-of-pocket expenses }\end{array}$ & $84(14.8)$ \\
\hline My insurance too complicated to figure out & $69(12.2)$ \\
\hline $\begin{array}{l}\text { The cost of having my uncontrollable urine leakage } \\
\text { evaluated is too high }\end{array}$ & $112(19.8)$ \\
\hline There is no transportation to the office or clinic & $250(44.1)$ \\
\hline The wait is too long at the time of the appointment & $335(59.1)$ \\
\hline The office or clinic is too far away & $284(50.1)$ \\
\hline Appointments have to be scheduled too far ahead & $236(4 \mid .6)$ \\
\hline Office hours at the office or clinic are limited & $182(32.1)$ \\
\hline I don't like to be examined or asked a lot of questions & $268(47.3)$ \\
\hline $\begin{array}{l}\text { The physician or nurse practitioner doesn't take time } \\
\text { to explain what he or she is doing or why, or answer } \\
\text { my questions }\end{array}$ & $227(40.0)$ \\
\hline I am afraid to find out if I have a serious problem & $218(38.5)$ \\
\hline $\begin{array}{l}\text { For some reason, I am afraid of the health } \\
\text { care practitioner }\end{array}$ & $337(59.4)$ \\
\hline $\begin{array}{l}\text { The health care practitioner and staff aren't interested } \\
\text { in my worries about my health }\end{array}$ & $202(35.6)$ \\
\hline
\end{tabular}


a decreased probability of seeking care for incontinence. ${ }^{5,9}$ The ICIQ-UI SF consists of a three-item scale with items related to frequency and amount of urinary incontinence and quality of life (see Table 2). An overall ICIQ-UI SF score is calculated as the summation of all three scales. Higher incontinence scores are associated with increased severity of urinary incontinence. ${ }^{6,8}$ Both questionnaires are Likert format instruments. All patients completed a paper version of a demographics questionnaire, the ICIQ-UI SF, and the BICS-Q, and were separated into groups by gender.

\section{Analysis}

Descriptive statistics were used to summarize patient data. The nonparametric Mann-Whitney U test was used for statistical analyses, and statistical associations were sought using Chi-squared $\left(\chi^{2}\right)$ tests. Adjusted odds ratios (ORs) and $95 \%$ confidence intervals (CIs) for the main outcomes

Table 2 International Consultation on Incontinence Questionnaire-Urinary Incontinence Short Form ${ }^{6}$

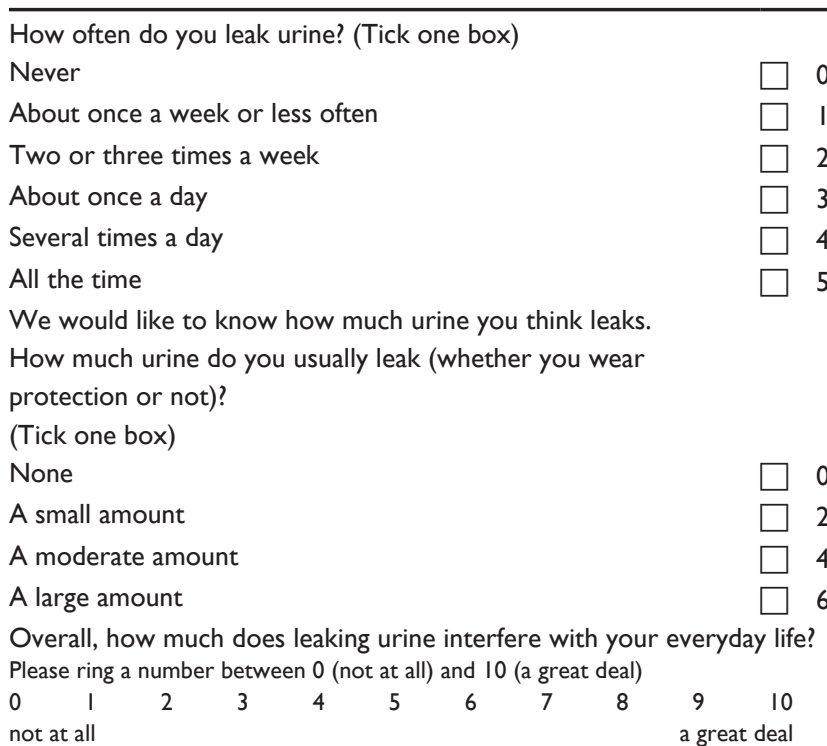

ICIQ score: sum scores

When does urine leak? (Please tick all that apply to you)

a) Never - urine does not leak

b) Leaks before you can get to the toilet

c) Leaks when you cough or sneeze

d) Leaks when you are asleep

e) Leaks when you are physically active/exercising

f) Leaks when you have finished urinating and are dressed

g) Leaks for no obvious reason

h) Leaks all the time

Notes: Stress urinary incontinence refers to involuntary leakage on effort or exertion, or on sneezing or coughing, ie, only (c) and/or (e). Urgency urinary incontinence refers to involuntary leakage accompanied by or immediately preceded by urgency, ie, only (b).

Abbreviation: ICIQ-UI SF, International Consultation on Incontinence Questionnaire-Urinary Incontinence Short Form. were obtained using multivariate logistic regression models, adjusted for BICS-Q score and patient gender. All statistical tests were performed at a significance level of 0.05 using the Statistical Package for the Social Sciences version 11.0 (SPSS inc, Chicago, IL).

\section{Results}

In total, 1014 patients randomly selected from 39 centers were identified by this study, and 567 patients (response rate $55.9 \%$ ) with urinary incontinence were finally evaluated using the inclusion and exclusion criteria described above. The mean age \pm standard deviation of the study group was $68.7 \pm 15.4$ (range 22-98) years. The mean total BICS-Q score was $7.5 \pm 7.3$ (range $0.0-42.0$ ), and the mean total ICIQ-UI SF score was $13.9 \pm 4.6$ (range 1.0-21.0). Participants were stratified into four groups based on their reported barriers to seeking care for incontinence: no barriers (300 patients, 52.9\%), mild barriers (BICS-Q $<5 ; 150$ patients, 26.5\%), moderate barriers (BICS-Q 6-36; 116 patients, 20.5\%) and severe barriers (BICS-Q > 36; one patient, $0.1 \%$ ). The reliability of the questionnaires was measured with Cronbach's coefficient alpha using data provided by the total sample. The Cronbach's alpha coefficient was high for the total set of items in both the BICS-Q (0.91) and the ICIQ-UI SF (0.81).

The most frequent barriers to seeking care were participants' fear of the health care practitioner, long waiting times at appointments, and long distances to travel to the nearest clinic. Patients with mild to moderate levels of urinary incontinence (ICIQ-UI SF $\leq 12$ ) had a BICS-Q mean score of $5.9 \pm 5.4$, and patients with severe to very severe levels of urinary incontinence (ICIQ-UI SF $\geq 13$ ) had a BICS-Q mean score of $8.3 \pm 8.0$. This difference was statistically significant $(P<0.05)$. These findings support the notion that patients with severe urinary incontinence have a decreased probability of seeking care for incontinence.

The study group consisted of 147 males (25.9\%) and 420 females (74.1\%). The mean BICS-Q score was $7.4 \pm 6.9$ in females and $7.7 \pm 8.4$ in males, and the mean ICIQ-UI SF score was $13.6 \pm 4.6$ in females and $14.6 \pm 4.7$ in males. Patients were divided into four groups based on treatment for urinary incontinence and gender. Among the male patients, 93 $(63.3 \%)$ reported no treatment for their urinary incontinence and $282(67.1 \%)$ of the female patients reported no such treatment. Statistically significant differences between treated and nontreated patients were found according to age and body mass index among females and according to history of prostatectomy and education among males. Treated males had significantly lower BICS-Q scores (see Tables 3 and 4). 
Table 3 Demographic and medical characteristics of patients with urinary incontinence

\begin{tabular}{|c|c|c|c|c|c|c|}
\hline & \multicolumn{6}{|c|}{ Patients with urinary incontinence } \\
\hline & $\begin{array}{l}\text { Treated } \\
\text { females } \\
(n=138)\end{array}$ & $\begin{array}{l}\text { Untreated } \\
\text { females } \\
(\mathrm{n}=\mathbf{2 8 2})\end{array}$ & $P$ value & $\begin{array}{l}\text { Treated } \\
\text { males } \\
(n=54)\end{array}$ & $\begin{array}{l}\text { Untreated } \\
\text { males } \\
(n=93)\end{array}$ & $P$ value \\
\hline \multicolumn{7}{|l|}{ Age } \\
\hline Mean (SD) & $66.7 \pm 11.02$ & $70.0 \pm 12.35$ & $0.003^{\mathrm{a}}$ & $73.1 \pm 10.45$ & $71.7 \pm 11.6$ & $0.625^{\mathrm{a}}$ \\
\hline Range & $(38-89)$ & $(22-98)$ & & $(42-92)$ & $(23-94)$ & \\
\hline \multicolumn{7}{|l|}{ BMI $\left(\mathrm{kg} / \mathrm{m}^{2}\right)$} \\
\hline Mean (SD) & $29.2 \pm 4.68$ & $27.1 \pm 4.04$ & $<0.00 \mathrm{I}^{\mathrm{a}}$ & $27.1 \pm 3.94$ & $27.1 \pm 3.66$ & $0.917^{\mathrm{a}}$ \\
\hline Range & $(18.94-51.11)$ & $(16.98-40.28)$ & & $(17.57-36.36)$ & $(16.16-37.11)$ & \\
\hline \multicolumn{7}{|l|}{ Parity } \\
\hline Mean (SD) & $2.4 \pm 1.24$ & $2.6 \pm 1.39$ & $0.112^{\mathrm{a}}$ & - & - & \\
\hline Range & $(0-6)$ & $(0-7)$ & & & & \\
\hline Hysterectomy (\%) & $30(21.7 \%)$ & 71 (25.2\%) & $0.439^{b}$ & - & - & \\
\hline Prostatectomy (\%) & - & - & & $23(42.6 \%)$ & $\mathrm{II}(\mathrm{II} .8 \%)$ & $<0.00 \mathrm{I}^{\mathrm{b}}$ \\
\hline \multicolumn{7}{|l|}{ Education } \\
\hline Compulsory & $64(46.4 \%)$ & $160(56.7 \%)$ & $0.128^{b}$ & 17 (3I.5\%) & $50(53.8 \%)$ & $0.002^{\mathrm{b}}$ \\
\hline Post compulsory & $70(50.7 \%)$ & II 4 (40.4\%) & & $3 \mathrm{I}(57.4 \%)$ & $42(45.2 \%)$ & \\
\hline University & $4(2.9 \%)$ & $8(2.8 \%)$ & & $6(11.1 \%)$ & I (I.I\%) & \\
\hline \multicolumn{7}{|l|}{ Marital status } \\
\hline Married & $74(53.6 \%)$ & 149 (52.8\%) & $0.879^{b}$ & 31 (57.4\%) & $62(66.7 \%)$ & $0.26 \mathrm{I}^{\mathrm{b}}$ \\
\hline Unmarried & $64(46.4 \%)$ & I 33 (47.2\%) & & $23(42.6 \%)$ & 31 (33.3\%) & \\
\hline \multicolumn{7}{|l|}{ Duration of urinary } \\
\hline \multicolumn{7}{|l|}{ incontinence (years) } \\
\hline Mean (SD) & $5.1 \pm 3.76$ & $4.8 \pm 4.25$ & $0.10 I^{\mathrm{a}}$ & $4.6 \pm 3.12$ & $5.1 \pm 4.09$ & $0.75 \mathrm{I}^{\mathrm{a}}$ \\
\hline Range & $(0-20)$ & $(0-28)$ & & $(0-12)$ & $(0-20)$ & \\
\hline
\end{tabular}

Notes: Mean difference between groups is statistically significant at the 0.05 level. a Mann-Whitney $U$ test; ${ }^{\text {b}}$ Chi-squared test.

Abbreviations: BMI, body mass index; SD, standard deviation.

Adjusted odds ratio by gender (OR) revealed risk factors that might influence seeking health care (see Table 5). Females with obesity were $113 \%$ more likely not to seek care (females versus males; OR 2.13, 95\% confidence interval [CI] 1.35-3.34 versus OR $0.83,95 \%$ CI $0.36-1.93$ ), stress urinary incontinence were probability $57 \%$ (OR $1.57,95 \%$ CI $0.94-2.36$ versus OR 9.38, 95\% CI 1.07-12.62), and urgency urinary incontinence were probability $140 \%$ (OR $2.40,95 \%$ CI $1.49-3.87$ versus OR $1.75,95 \%$ CI $0.84-2.65$ ) but females with a BICS-Q score $>20$ were only $9 \%$ more likely not to seek care (OR 1.09, 95\% CI 0.45-2.65 versus OR 3.06, 95\% CI 1.05-9.89). All of these differences were statistically significant. Duration of urinary incontinence longer than 5 years had a slightly stronger association with probability of not seeking care in females than in males (OR $1.21,95 \%$ CI $0.77-1.88$ versus OR $0.51,95 \%$ CI $0.23-1.13)$. History of hysterectomy and prostatectomy were low risk factors as barriers to seeking care for incontinence (OR $0.83,95 \%$ CI $0.51-1.34$ versus OR $0.18,95 \%$ CI $0.08-0.41$ ).

Table 4 BICS-Q and ICIQ-UI SF scores in patients with urinary incontinence

\begin{tabular}{|c|c|c|c|c|c|c|}
\hline & \multicolumn{6}{|c|}{ Patients with urinary incontinence } \\
\hline & $\begin{array}{l}\text { Treated } \\
\text { females } \\
(n=138)\end{array}$ & $\begin{array}{l}\text { Untreated } \\
\text { females } \\
(\mathrm{n}=\mathbf{2 8 2})\end{array}$ & $P$ value & $\begin{array}{l}\text { Treated } \\
\text { males } \\
(n=54)\end{array}$ & $\begin{array}{l}\text { Untreated } \\
\text { males } \\
(n=93)\end{array}$ & $P$ value \\
\hline \multicolumn{7}{|l|}{$\mathrm{BICS}-\mathrm{Q}$} \\
\hline Mean (SD) & $7.6 \pm 7.17$ & $7.3 \pm 6.76$ & 0.933 & $6.3 \pm 7.73$ & $10.1 \pm 9.04$ & 0.005 \\
\hline Range & $(0-30)$ & $(0-32)$ & & $(0-42)$ & $(0-34)$ & \\
\hline \multicolumn{7}{|l|}{ ICIQ-UI SF } \\
\hline Mean (SD) & $13.9 \pm 3.79$ & $13.4 \pm 4.90$ & 0.522 & $14.7 \pm 4.25$ & $14.5 \pm 4.99$ & 0.912 \\
\hline Range & $(6-21)$ & $(I-2 I)$ & & $(5-21)$ & $(3-2 I)$ & \\
\hline
\end{tabular}

Note: Mean difference between groups is statistically significant at the 0.05 level (Mann-Whitney $U$ test). ICIQ-UI SF score ranges from 0 (no urinary incontinence) to 21 (very severe level of urinary incontinence).

Abbreviations: BICS-Q, Incontinence Care Seeking Questionnaire; ICIQ-UI SF, International Consultation on Incontinence Questionnaire-Urinary Incontinence Short Form; SD, standard deviation. 
Table 5 Adjusted odds ratios of barriers to seeking care for incontinence by gender

\begin{tabular}{|c|c|c|c|c|}
\hline & \multicolumn{2}{|c|}{ Males } & \multicolumn{2}{|c|}{ Females } \\
\hline & OR & $95 \% \mathrm{Cl}$ & OR & $95 \% \mathrm{Cl}$ \\
\hline Age $>70$ years & 0.95 & $0.47-1.94$ & 0.68 & $0.45-1.03$ \\
\hline Education non-university & $0.40^{*}$ & $0.20-0.80$ & 0.71 & $0.47-1.07$ \\
\hline Obesity (BMI > 30) & 0.83 & $0.36-1.93$ & $2.13^{*}$ & $1.35-3.34$ \\
\hline Duration of $U I>5$ years & $0.5 \mathrm{I}$ & $0.23-1.13$ & 1.21 & $0.77-1.88$ \\
\hline Hysterectomy & - & - & 0.83 & $0.5 \mathrm{I}-\mathrm{I} .34$ \\
\hline Prostatectomy & $0.18^{*}$ & $0.08-0.41$ & - & - \\
\hline Stress incontinence & $9.38^{*}$ & $1.07-12.62$ & 1.57 & $0.94-2.36$ \\
\hline Urgency incontinence & 1.75 & $0.84-2.65$ & $2.40 *$ & I.49-3.87 \\
\hline $\mathrm{BICS}>20$ & $3.06 *$ & $1.05-9.89$ & 1.09 & $0.45-2.65$ \\
\hline ICIQ-UI SF > 12 & 1.05 & $0.49-2.25$ & 1.39 & $0.90-2.13$ \\
\hline
\end{tabular}

Notes: Barriers were defined by BICS-Q $\geq I$ and untreated urinary incontinence. * Statistically significant difference at 0.05 level.

Abbreviations: BICS-Q, Incontinence Care Seeking Questionnaire; BMI, body mass index; ICIQ-UI SF, International Consultation on Incontinence QuestionnaireUrinary Incontinence Short Form; OR, adjusted odds ratio by gender and BICS-Q; $\mathrm{Cl}$, confidence intervals of odds ratio; $\mathrm{UI}$, urinary incontinence.

\section{Discussion}

To our knowledge, this is the first European study on gender-specific differences that might influence seeking of health care for urinary incontinence that has shown a different probability of not seeking care between incontinent females and males. The most important determinants of the probability of seeking health care were type and duration of urinary incontinence, body mass index, education, and BICS-Q score $>20$.

External barriers to seeking care differ from internal barriers, the latter being attitudes or beliefs that prevent incontinence sufferers from seeking care, such as embarrassment, fear, or anxiety. Disparities in seeking health care for some medical conditions can be explained by socioeconomic differences in barriers to care for sufferers. ${ }^{5}$ Urinary incontinence is a relatively common disease with a significant impact on quality of life. There are no gender differences in prevalence of urinary incontinence in the elderly. ${ }^{2,10}$ Treatment of urinary incontinence is often foregone due to a decision taken by the patient not to seek care, which is evident in our findings. ${ }^{11-13}$

Variation in the health care systems of different countries determines the reasons given by people for not seeking treatment for urinary incontinence. ${ }^{14-16}$ Patients give many reasons for not seeking treatment, including lack of perception of urinary incontinence as abnormal or serious, a belief that urinary incontinence is a normal part of ageing, embarrassment, low expectation of treatment success, and a belief that they should cope on their own. Several studies have identified factors associated with seeking care for urinary incontinence, including severity, duration, and type of urinary incontinence, nocturnal symptoms, and the bother or impact of urinary incontinence..$^{2,17-19}$

Barriers originate in insufficient motivation of patients to seek care for incontinence. In some countries, motivation often comes with spousal input, the deleterious impact of urinary incontinence on quality of life, low work efficiency, changes in lower urinary tract symptoms, or the necessity of health care for different reasons. Patients experience barriers both before and during investigation by a physician because of embarrassment as a result of the intimate nature of urinary incontinence. Patients do not have access to information about specific barriers to seeking care for urinary incontinence. ${ }^{20-23}$

Patients seeking treatment for urinary incontinence at the time of consultation were not included in this prospective cross-sectional study. This study quantified barriers, described the occurrence of barriers in the incontinent patient population, and calculated ORs with respect to the different factors. Most of the barriers to seeking care were mild or moderate.

The BICS-Q was created on the basis of psychometric analyses of barriers in incontinent patients. ${ }^{5}$ Some authors do not agree with this form of psychometric quantification due to the different health and social problems in low-income countries. ${ }^{13,14}$ Despite the differences between health policies in the US and Europe, the BICS-Q should be suitable for quantification of barriers in either setting. Our study used the BICS-Q as a reasonable tool for measurement and quantification of barriers to seeking care for incontinence in central Europe. Further use of the BICS-Q may clarify different aspects of barriers with respect to the varying health care environments of different countries.

Access to primary health care could be an important determinant of barriers to seeking health care for incontinence. A patient will avoid a basic evaluation of urinary incontinence if he or she is afraid of the health care practitioner, if the waiting time at the clinic is too long, or if it takes a long time to travel to the nearest clinic. In this study, these were the most frequent barriers (in nearly $50 \%$ of cases). Discussion about urinary incontinence in primary health care is necessary for patients to improve their knowledge and motivation to pursue successful treatment. ${ }^{15,19,22,24}$

In an epidemiological survey done in a sample of Middle Eastern women, barriers to seeking consultation for urinary incontinence were embarrassment (67.2\%), the assumption that urinary incontinence was normal in older age or after giving birth to multiple children (46.7\%), choice of 
self-treatment $(39.2 \%)$, low expectations of medical care $(38.2 \%)$, the belief that urinary incontinence may resolve spontaneously $(15.8 \%)$, and the belief that treatment would be costly $(12.6 \%)$. ORs have revealed some of the important barriers in severe or stress urinary incontinence because females were $169 \%$ or $141 \%$ more likely not to seek care. ${ }^{20}$

We found that the impact of health care providers is an important external barrier to seeking care for incontinence (59.4\% of cases). Stress urinary incontinence was more important in males than in females because males versus females were $838 \%$ versus $57 \%$, respectively, more likely not to seek care. Males had lower ORs than females for urge urinary incontinence; they were $75 \%$ versus $140 \%$ more likely not to seek care. We did not evaluate age-related changes in the level of urinary incontinence.

This study raises the possibility of influencing the thinking of patients and physicians with regard to barriers to seeking care for urinary incontinence. Sufferers with a higher risk of barriers must be motivated to decrease their internal barriers and to communicate their external barriers to health care. The ICIQ-UI SF questionnaire is suitable for basic evaluation of incontinent patients and quantification of urinary leakage. This diagnostic tool can improve the basic evaluation of urinary incontinence by general practitioners and provide simple treatment in the early stages of the problem..$^{2,6,7}$

\section{Conclusion}

We conclude that external barriers to seeking care for incontinence are gender-specific. Females with obesity and urge urinary incontinence and males with stress urinary incontinence reported more suffering than others. Because longer life expectancy is likely to increase the size of the ageing population, our results may contribute to improved health care for the incontinent population in the future. Identification of barriers to seeking care for incontinence can help to guide the creation of effective social and health programs and policies. Gender-specific barriers must be taken into account when making health care decisions concerning individuals with urinary incontinence. However, patients with a higher risk of barriers have to be motivated to manage their urinary incontinence.

\section{Acknowledgments}

The authors thank Marica Lascekova and Jan Micanko for their support with data analysis and Patrick Butler for language revision. This work was supported by the Centre of Excellence for Perinatology Research (ITMS codes
26220120016 and 26220120036) cofunded by European Union sources.

\section{Disclosure}

The authors report no conflicts of interest in this work.

\section{References}

1. Abrams P, Cardozo L, Fall M, et al. The Standardization of Terminology of Lower Urinary Tract Function: Report from the Standardization Sub-committee of the International Continence Society. Neurourol Urodyn. 2002;21:167-178.

2. Milsom I, Altman D, Lapitan MC, Nelson R, Sillen U, Thom D. Epidemiology of urinary (UI) and faecal (FI) incontinence and pelvic organ prolapse (POP). In: Abrams C, Cardozo L, Kouhry S, Wein A, editors. Incontinence. Paris, France: Health Publications Ltd; 2009.

3. Staskin D, Kelleher C, Avery K, et al. Initial assessment of urinary and faecal incontinence in adult male and female patients. In: Abrams C, Cardozo L, Kouhry S, Wein A, editors. Incontinence. Paris, France: Health Publications Ltd; 2009.

4. Bushnell DM, Martin ML, Summers KH, Svihra J, Lionis CH, Donald PL. Quality of life of women with urinary incontinence: cross-cultural performance of 15 language versions of the I-QOL. Qual Life Res. 2005;14:1901-1913.

5. Heit M, Blackwell L, Kelly S. Measuring barriers to incontinence care seeking. Neurourol Urodyn. 2008;27:174-178.

6. Avery K, Donovan J, Peters TJ, Shaw C, Gotoh M, Abrams P. A brief and robust measure for evaluating the symptoms and impact of urinary incontinence. Neurourol Urodyn. 2004;23:322-330.

7. Klovning A, Avery K, Sandvik H, Hunskaar S. Comparison of two questionnaires for assessing the severity of urinary incontinence: the ICIQ-UI SF versus the Incontinence Severity Index. Neurourol Urodyn. 2009;28:411-415.

8. Svihra J, Avery K, Sopilko I, Kliment J. Slovak version of a new questionnaire for urinary incontinence: the International Consultation on Incontinence Questionnaire Short Form ICIQ-UI SF. Urologia. 2004;10:34. Italian.

9. Svihra J, Luptak J, Kliment J, Svihrova V, Lascekova M. Gender specific barriers to incontinence care seeking. Abstract 385 presented at the joint annual meeting of the International Continence Society and International Urogynecological Association, August 22-27, 2010, Toronto, Canada.

10. Thom DH, van den Eeden SK, Ragins AI, et al. Differences in prevalence of urinary incontinence by race/ethnicity. J Urol. 2006;175:259-264.

11. Lalos O, Kjellberg L, Lalos A. Urinary, climacteric and sexual symptoms 1 year after treatment of cervical cancer without brachytherapy. J Psychosom Obstet Gynaecol. 2009;30:269-274.

12. Mautner E, Greimel E, Trutnovsky G, Daghofer F, Egger JW, Lang U. Quality of life outcomes in pregnancy and postpartum complicated by hypertensive disorders, gestational diabetes, and preterm birth. J Psychosom Obstet Gynaecol. 2009;30:231-237.

13. Rizk DE, Shaheen H, Thomas L, Dunn E, Hassan MY. The prevalence and determinants of health care-seeking behavior for urinary incontinence in United Arab Emirates women. Int Urogynecol J Pelvic Floor Dysfunct. 1999;10:160-165.

14. Burgio KL, Ives DG, Locher J, Arena VC, Kuller LH. Treatment seeking for urinary incontinence in older adults. J Am Geriatr Soc. 1994;42: 208-212.

15. Sandvik H, Kveine E, Hunskaar S. Female urinary incontinence psychosocial impact, self-care and consultations. Scand J Caring Sci. 1993; 7:53-56.

16. Shaw C, Brittain K, Tansey R, Williams K. How people decide to seek health care: a qualitative study. Int J Nurs Stud. 2008;45:1516-1524.

17. Basu M, Duckett JR. Barriers to seeking treatment for women with persistent or recurrent symptoms in urogynaecology. BJOG. 2009;116: 726-730. 
18. Morrill M, Lukacz ES, Lawrence JM, Nager CW, Contreras R, Luber KM. Seeking healthcare for pelvic floor disorders: a populationbased study. Am J Obstet Gynecol. 2007;197:86. e1-e6.

19. Svihra J, Baska T, Martin ML, et al. Prevalence of female overactive bladder with urinary incontinence in Slovakia. Eur Urol. 2002;1:85.

20. El-Azab AS, Shaaban OM. Measuring the barriers against seeking consultation for urinary incontinence among Middle Eastern women. BMC Women's Health. 2010;10:3.

21. Kinchen KS, Burgio K, Diokno AC, Fultz NH, Bump R, Obenchain R. Factors associated with women's decisions to seek treatment for urinary incontinence. J Womens Health (Larchmont). 2003;12:687-698.
22. O’Donnell M, Lose G, Sykes D, Voss S, Hunskaar S. Help-seeking behaviour and associated factors among women with urinary incontinence in France, Germany, Spain and the United Kingdom. Eur Urol. 2005;47:385-392.

23. Reymert J, Hunskaar S. Why do only a minority of perimenopausal women with urinary incontinence consult a doctor? Scand J Prim Health Care. 1994;12:180-183.

24. Zamecnik L, Hanus T, Jarolim L. Interstitial cystitis. Endoskopie. 1999; 8:2-6.

\section{Publish your work in this journal}

Patient Preference and Adherence is an international, peer-reviewed, open access journal focusing on the growing importance of patient preference and adherence throughout the therapeutic continuum. Patient satisfaction, acceptability, quality of life, compliance, persistence and their role in developing new therapeutic modalities and compounds to optimize clinical outcomes for existing disease states are major areas of interest. This journal has been accepted for indexing on PubMed Central. The manuscript management system is completely online and includes a very quick and fair peer-review system. Visit http://www.dovepress.com/ testimonials.php to read real quotes from published authors.

Submit your manuscript here: http://www.dovepress.com/patient-preference-and-adherence-journal 